\title{
Nilai-Nilai Karakter Pengguna Bahasa Arab Perspektif I'rab Nahwu
}

\author{
Adi Supardi ${ }^{1}$
}

DOI: https://doi.org/10.52593/klm.02.1.03

Naskah diterima: 09-01-2021, direvisi: 22-01-2021, disetujui: 25-01-2021

\begin{abstract}
Abstraksi
Penelitian ini berasumsi dari kebutuhan nilai-nilai pendidikan karakter yang perlu ditanamkan bagi pengguna bahasa Arab. Tujuan penelitian ini untuk mengetahui nilai-nilai karakter bagi pengguna bahasa Arab menggunakan pendekatan kontekstual filosofis I'rab Nahwu. Penelitian ini menggunakan penelitian kualitatif, yang berbentuk library reseach (penelitian pustaka) dengan menggunakan metode analisis deskriftif kitab klasik al-Jurûmiyah dengan pendekatan kitab pensyarahnya yaitu Asymawiy karya Syekh Abdullâh ibn Fadhîl al-Asymawiy dan Kitab al-Kafrawy ala Matn al-Jurûmiyah karya Syekh Hasan al-Kafrawy. Hasil penelitian ini menunjukan nilai-nilai kontekstual yang bermanfaat bagi pengguna bahasa Arab, yaitu rofa' meliputi nilai semangat yang tinggi dan kontribusi yang besar; nashab meliputi nilai integritas dan objektifitas; khofad meliputi nilai rendah hati dan apresiatif dan jazm meliputi nilai orientasi ibadah dalam bekerja dengan ikhlas dan amanah.
\end{abstract}

Kata Kunci : I'rab Nahwu; al-Jurûmiyyah; Bahasa Arab; Karakter

\section{A. Pendahuluan}

Pembelajaran bahasa Arab harus mampu menjawab tantangan sejalan dengan jaman yang dilintasinya, maka berbagai inovasi terus dilakukan dalam pengembangan metodologi dan media pembelajaran bahasa Arab, hal ini akan mampu mendorong bahasa Arab agar dapat bersaing dan sejajar dengan bahasa lain -dalam pengertian bahasa asing yang dipelajari di Indonesia- saat ini.

Upaya ini terus dilakukan oleh para cendikiawan, guru dan/atau dosen bahasa Arab bahkan para pakar sebagai langkah dan upaya mewujudkan pengembangan sekaligus melestarikan pembelajaran yang menarik dan diminati oleh banyak kalangan, terlebih bagi umat Muslim sebagai pengguna utama bahasa Arab, baik dalam ritual ibadah maupun sebagai identitas keagamaannya.

Proses mencetak guru bahasa Arab memiliki dua tahapan pembinaan. Pertama, menyiapkan mereka (menjadi tenaga edukatif yang memahami dan menguasai materi dan metodologi) sebelum berkhidmah mengamalkan profesinya dan, Kedua ketika

\footnotetext{
${ }^{1}$ Universitas Islam Negeri Sunan Gunung Djati Bandung, supardiadi579@gmail.com
} 
mereka tengah melakukan misinya. ${ }^{2}$ Maka dianggap penting mempersiapkan kader pengguna bahasa Arab pada saat mereka terjun ke masyarakat.

Dalam situasi seperti ini, pengembangan metodologi dan media pembelajaran menjadi sebuah kebutuhan mendasar dalam menjaga eksistensi bahasa Arab, dengan semakin bermunculannya inovasi dan dinamisasi langkah-langkah pembelajaran bahasa Arab bagi penutur non-Arab akan berdampak besar pada tingkat minat mempelajari bahasa Arab di Indonesia. Ditambah lagi dengan munculnya beragam problematika internal bahasa Arab sendiri yang masih dianggap sulit oleh sementara orang. ${ }^{3}$

Inovasi pembelajaran bahasa Arab terus gencar dilakukan, bahkan di masa pandemi covid-19 ini, bermunculan pembelajaran berbasis digital melalui internet learning. Pembelajaran internet learning atau lebih dikenal dengan term dalam jaringan (daring/online) memang cukup diminati saat ini, karena dirasa membantu dan mampu mengantisipasi ketertinggalan materi akibat penerapan sosial berskala besar (PSSB) juga akibat social distanting atau pembatasan sosial yang menghendaki aktivitas jarak jauh, tidak menimbulkan kerumuman, tidak mengundang masa untuk berkumpul bahkan aktivitas pendidikan harus diliburkan untuk waktu tertentu.

Dengan semakin terbukanya peluang pengembangan metodologi dan media pembelajaran maka tantangan berikutnya mengarah pada ruh pengguna bahasa, yaitu guru bahasa Arab dan pengguna bahasa Arab pada umumnya, seperti kutipan:

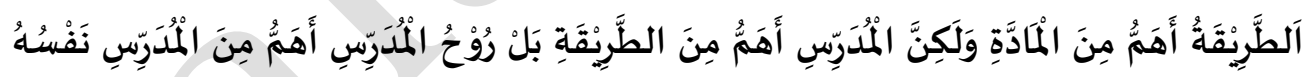

Artinya: "Metode lebih penting dari materi, sementara guru jauh lebih penting dari metode itu, tetapi ruh mengajar seorang guru sangat lebih penting dari guru sendiri ",

Bahasa Arab akan mampu menjawab tantangan arus globalisasi yang semakin pesat berkembang, jika diimbangi dengan penanaman nilai karakter guru dan pengguna bahasa Arab yang berfungsi untuk self controlling sebagai wujud implementasi akhlak mulia pada pribadi pengguna bahasa. Seiring dengan arus tantangan jaman yang semakin komplek dan massif ini, maka bukan tidak mungkin tantangan pembelajaran bahasa Arab bukan hanya bersumber pada wilayah teknis dan materi tapi lebih menekankan pada wilayah user atau pengguna bahasa itu sendiri. 2020), 172

${ }^{2}$ Asep M. Tamam. Bangsa dan Bahasa Arab dalam lintasan Sejarah. (Yogyakarta, LeKKas,

${ }^{3}$ Ahmad Izzan. Metodologi Pembelajaran Bahasa Arab. (Bandung, Humaniora, 2011), 62.

${ }^{4}$ Agus Tricahyo. Seminar Webinar Nasional. (Ponorogo, IAIN Ponorogo,2020), 1. 
Hal serupa juga diapirmasi oleh pendapat Syaikh Abdul Qadir Al-Quhin dalam kitab penomenalnya berjudul Maniyyah Al-Faqir Al-Munjarid wa Sairah Al-Murid AlMutafarrid, bahwa pengguna bahasa -secara sempit ilmu Nahwu- itu sebaiknya bukan hanya pandai Nahwu lisan (secara gramatika) tapi juga pandai secara Nahwu hati (karakter positif), sehingga selaras antara ucapan dan perbuatannya yang mengarah pada kebaikan dan kebermanfaatan untuk sesamanya. Mengetahui Nahwu hati lebih baku dan lebih bermanfaat daripada Nahwu lisan, menurut mereka yang jernih pikirannya. ${ }^{5}$

Maka, berakar pada kebutuhan akan materi teoritis dan praktis di atas, sebagai pengguna bahasa Arab dirasa perlu mengkaji lebih mendalam karakter positif ini sehingga mampu menyelaraskan sikap kemampuan berbahasa. Penelitian ini untuk menjawab kebutuhan tersebut, mengangkat ke permukaan nilai-nilai filosofis karakter dalam perspektif I'rab Nahwu dalam literer kitab klasik seperti kitab Al-Kafrawiy dan Al-Asymawiy, dengan pendekatan kontekstual karakter positif pengguna bahasa sesuai hirarki I'rab Nahwu yaitu rofa', nashab, khofad dan jazm.

\section{B. Konsep Pembahasan}

\section{Kondisi pengguna bahasa Arab di Indonesia}

Penelitian ini bersifat subjektif, penulis menilai bahwa sejalan dengan kebutuhan pengguna bahasa Arab (secara sempit guru atau dosen) dan umumnya seluruh pihak yang terlibat aktif melestarikan bahasa Arab, mereka pada wilayah operasional pendidikan selain bertindak sebagai guru atau dosen sering juga merangkap peran ganda sebagai ustadz dan tokoh masyarakat, sehingga hal demikian perlu kiranya ditanggapi serius dan mendapat perhatian. Karena bahasa dan berbahasa merupakan suatu dimensi yang berbeda tapi saling berkaitan, berbahasa ini melibatkan kemampuan psikologi dan persuasi moral yang baik terhadap lingkungan sekitar. ${ }^{6}$

Ketika kita berbicara tentang penyiapan guru bahasa Arab -termasuk guru bidang studi lain- yang professional, maka kita harus memiliki gambaran yang jelas di depan mata tentang masyarakat mana yang akan dipersiapakan guru bahasa Arabnya. Setelah itu kita harus mempelajari kecenderungan dan falsafah hidup serta nilai-nilai yang berlaku di dalam masyarakat tersebut. Kualitas penyiapan guru bahasa Arab yang

\footnotetext{
5 Syaikh Abdul Qadir Al-Kuhin. Nahwu Sufi. penerjemah Bahrudin Achmad. (Bekasi, AlMuqsith Pustaka, 2020), 36.

${ }^{6}$ Abdul Chaer, Psikolinguistik Kajian Teoretik. (Jakarta, Penerbit Rineka Cipta, 2019), 6.
} 
lemah akan berimbas pada lemahanya kualitas calon guru bahasa Arab. ${ }^{7}$ Maka mengajar bahasa Arab bukan saja persoalan menyampaikan materi dan menilai, tapi berfungsi sebagai pihak yang ikut berkontribusi menyiapkan kualitas moral dan mental peserta didik yang optimal dan matang.

Kondisi ini menuntut para guru dan dosen bahasa Arab agar berlaku profesional sebagai pendidik, juga disaat yang nyaris bersamaan harus memainkan peran lain sebagai sosok ustaz (kiai/ajeungan) juga tokoh masyarakat seperti mendapat kepercayaan untuk mengelola lembaga pesantren, penasihat desa, MUI desa bahkan tingkat kota kabupaten, dan peran lain dalam kerangka bermanfaatan masyarakat.

Hal yang mendasari munculnya kondisi ini, didorong oleh posisi pundamental yang melekat pada diri pengguna bahasa Arab, selain sebagai pendidik professional juga kecenderungan masyarakat Indonesia untuk memberi label dan apresiasi kepada pengguna bahasa Arab sebagai ustadz atau tokoh, seperti telah terjadi pada guru atau dosen Pendidikan Agama Islam (PAI), karena pengguna bahasa Arab dianggap paham dan memiliki wawasan luas tentang Islam dengan penguasaan bahasa Arabnya.

Maka boleh jadi kondisi demikian, menjadi anugerah sekaligus amanah akan tantangan bagi pengguna bahasa Arab agar lebih lihai dalam memainkan peran sosialnya di masyarakat, karena kepercayaan masyarakat yang begitu besar, harus diimbangi kiranya dengan karakter positif sebagai pihak yang terlibat langsung menghidupkan bahasa Alquran.

\section{Faktor pendukung dan penghambat pengguna bahasa Arab}

Dalam kerangka nawacita pendidik professional bahasa Arab, pengguna bahasa Arab mempunyai faktor pendukung dan faktor penghambat, beberapa faktor ini lahir dan muncul seiring peran yang dimainkan oleh pengguna bahasa Arab di masyarakat, semakin besar peran di masyarakat tentu tantangan akan semakin besar pula, sehingga menuntut agar bersikap lebih selektif dalam menentukan prioritas.

\section{a. Faktor pendukung}

Berikut beberapa faktor pendukung pengguna bahasa Arab di masyarakat, yaitu:

1) Masyarakat cenderung menilai bahwa pengguna bahasa Arab memiliki kemampuan ilmu agama yang baik di banding pihak lain;

\footnotetext{
${ }^{7}$ Uril Bahruddin, Tathwîr Manhaj Ta'lîm al-Lughah al- 'Arabiyah (Malang, UIN Malang Press, 2010), 11.
} 
2) Latar belakang pengguna bahasa Arab mayoritas santri di pesantren;

3) Pengguna bahasa Arab mendapat kepercayaan yang cukup besar dalam amanah berbagai kegiatan sosial masyarakat;

4) Pengguna bahasa Arab dinilai aktif dan mau terlibat di masyarakat;

5) Berbagai posisi strategis di masyarakat banyak menguntungkan pengguna bahasa Arab karena sesuai dengan kemampuannya.

\section{b. Faktor penghambat}

Berikut beberapa faktor penghambat pengguna bahasa Arab di masyarakat, yaitu:

1) Sebagian pengguna bahasa Arab belum memiliki kepercayaan diri yang penuh untuk terjun di masyarakat;

2) Sebagian pengguna bahasa Arab belum optimal dalam eksistensi peran mereka di masyarakat sehingga malu untuk bergaul;

\section{Metode Penelitian}

Penelitian yang ditempuh menggunakan jenis penelitian kepustakaan (library research), yaitu studi dengan mengamati buku-buku, jurnal-jurnal, atau kitab kuning yang bersumber dari khazanah kepustakaan yang relevan dengan permasalahan yang diangkat dalam penelitian ini dengan bahan-bahan rujukan berasal dari data yang tertulis. ${ }^{8}$ Penelitian ini adalah bersifat kualitatif. Yaitu jenis penelitian yang memperoleh data deskriptif berupa informasi tertulis atau lisan dari orag-orang atau perilaku yang dapat diamati yang diarahkan pada latar dan individu secara holistik (utuh). ${ }^{9}$ Maka sejauh penelitian ini dilakukan, data yang diperoleh dari lapangan tidak bersifat angka statistik tapi mengarah pada gagasan konseptual yang kemudian disajikan melalui pendekatan kontekstual kebutuhan nilai-nilai praktis, bersifat subjektif dan melibatkan kebutuhan hirarkis penguna bahasa persfektif I'rab Nahwu pada pendapat dua tokoh ulama' Nahwu klasik yaitu kitab Asymawiy dan Kitab al-Kafrawy ala Matn alJurûmiyah.

\section{Hasil Penelitian dan Pembahasan}

\section{Wawasan I'rab Nahwu dalam Memetakan Pengguna bahasa Arab}

\footnotetext{
${ }^{8}$ Baharuddin. Paradigma Psikologi Islam. (Yogyakarta: Pustaka Pelajar, 2004), 53.

${ }^{9}$ Heri Gunawan. Dasar-dasar Metodologi Penelitian Pendidikan. (Fakultas Tarbiyah dan Keguruan UIN Sunan Gunung Djati Bandung, 2017), 28.
} 
Kalamuna, Vol. 2. No. 1 Januari 2021.37-49

Ilmu Nahwu yang menurut sebagian orang sulit dicerna, ilmu hapalan bahkan khusus bagi mereka yang akan mengkaji ilmu Islam semata. Namun, akan coba diuraikan dalam konsep filosofis (pendekatan makna tersirat). I'rab Nahwu dalam penelitian ini bersumber dari dua kitab klasik yaitu kitab al-Jurûmiyah dengan pendekatan kitab pensyarahnya yaitu Asymawiy karya Syekh Abdullâh ibn Fadhîl alAsymawiy dan Kitab al-Kafrawy ala Matn al-Jurûmiyah karya Syekh Hasan alKafrawy.

Diduga kuat, penelitian ini dirasa penting karena sebelumnya hanya sebatas kajian-kajian sederhana oleh Ulama klasik yang disampaikan melalui lisan kepada para santrinya dan belum banyak dipublikasikan di muka umum dalam bentuk karya ilmiah. Mari simak dahulu definisi I'rab secara terminologi ilmu Nahwu:

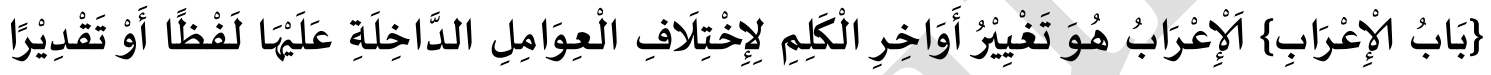

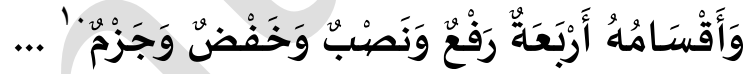

“Bab I'rab: I'rab adalah perubahan harakat ujung tiap-tiap kalimat karena amil (keharusan) yang masuk dalam kalimat itu baik secara lafadz maupun perkiraan, adapun pembagian I'rab ada empat yaitu rofa', nashab, khofad dan jazm ..."

Berikut contoh I'rab Nahwu ditinjau dari terminologi ilmu Nahwu di atas:

1. قَاَمَ مُحَمَمَّد ا (kata Muhammad termasuk I'rab rofa' dengan cirinya dhomah di akhir karena termasuk isim mufrod).

2. ضشَرَبَ عَلِيُ الَلْقِطَّ (kata al-qitto termasuk I'rab nashob dengan cirinya fathah di akhir karena termasuk isim mufrad).

3. جَلَسَ بَكْرُ في الْمَسنْجِدِ (kata fi al-masjidi termasuk I'rab khofad dengan cirinya kasrah di akhir karena termasuk isim mufrad).

\footnotetext{
${ }^{10}$ Asymawiy. Syekh Abdullâh ibn Fadhîl al-Asymawiy (Semarang, Maktabah Ulumiyah. t.t).
} 
4. لَمْ يَضْرِبْ (kata yadhrib termasuk I'rab jazm dengan cirinya sukun di akhir karena fiil mudhari shohihul akhir).

Hirarkis dan makna filosofis I'rab Nahwu bersumber dari rujukan kitab Asymawy karya Syekh Abdullah ibn Fadhil al-Asymawy, penerbit maktabah Ulumiyah Semarang dan Kitab al-Kafrawy ala Matn al-Jurumiyah karya Syekh Hasan alKafrawy, al-Haramain, Sanqofuroh Jeddah. sebagai berikut:

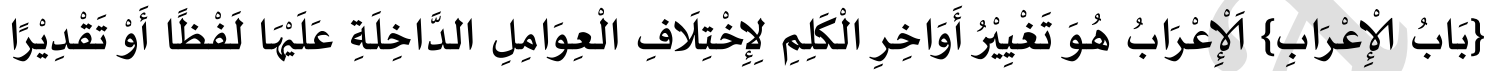

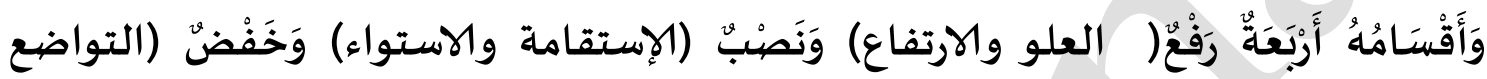

\section{والخضوع) وَجَزْمُ ( القطع ) "}

Untuk mempermudah pembaca, penulis sajikan dalam bentuk table berikut:

\begin{tabular}{|c|c|c|c|c|}
\hline No. & I'rab & $\begin{array}{l}\text { Ciri } \\
\text { Utama }\end{array}$ & Makna Filosofi & Artinya \\
\hline 1 & $\begin{array}{l}\text { Rofa } \\
\text { (رف) }\end{array}$ & Dhomah & $\begin{array}{c}\text { العلو والارتفاع } \\
\text { (al-uluwu wa al-irtifaau) }\end{array}$ & $\begin{array}{l}\text { Sesuatu yang tinggi dan } \\
\text { posisi puncak }\end{array}$ \\
\hline 2 & $\begin{array}{l}\text { Nashab } \\
\text { (نصب) }\end{array}$ & Fathah & $\begin{array}{c}\text { الإستقامة والاستواء } \\
\text { (al-istiqomatu wa al- } \\
\text { istiwau) }\end{array}$ & $\begin{array}{l}\text { Istikamah, konsisten, dan } \\
\text { integritas tinggi }\end{array}$ \\
\hline 3 & $\begin{array}{l}\text { Khofad } \\
\text { (خفض) }\end{array}$ & Kasrah & التواضع والخضوع & $\begin{array}{l}\text { Rendah hati dan } \\
\text { apresiatif }\end{array}$ \\
\hline
\end{tabular}

${ }^{11}$ Syekh Abdullâh ibn Fadhîl al-Asymawiy .Asymawiy. (Semarang, Maktabah Ulumiyah. t.t), 67. 
Kalamuna, Vol. 2. No. 1 Januari 2021.37-49

\begin{tabular}{|l|l|l|c|l|}
\hline & & $\begin{array}{c}\text { (al-tawadhu'wa al- } \\
\text { khudu') }\end{array}$ & \\
\hline 4 & Jazm & Sukun & القطع & $\begin{array}{l}\text { Putus dan fokus orientasi } \\
\text { ibadah kepada Allah }\end{array}$ \\
(al-qot'u) & & (alo & \\
\hline
\end{tabular}

Tabel 1: Hirarkis Filosofis I'rab Nahwu

Setelah mengamati deskripsi di atas, Penulis memperoleh informasi terkait definisi I'rab secara terminologi berikut contohnya dalam tinjauan filosofis. Makna filosofis dalam tabel di atas, menjadi grand teory dan sumber informasi pokok yang akan kita gali nilai-nilai kontekstualnya pada wilayah implementasi bagi nilai-nilai karakter pengguna bahasa Arab.

Secara literer terkait filosofis Nahwu dalam tinjauan beberapa disiplin ilmu memang cukup banyak ditemukan, hanya tidak cukup banyak yang telah dipublikasikan secara ilmiah. Bahkan, buku rujukan pokok penelitian ini yaitu kitab al-Jurûmiyyah karya Syaikh Muhammad Ash-Shunhajy ternyata memiliki pengaruh besar dalam bidang ilmu Nahwu, sehingga karyanya tersebut mendapatkan perhatian dari banyak ulama, hal ini terbukti dengan bermunculannya pensyarah dan hasyiah dari kitab alJurûmiyyah.

\section{Implementasi karakter pengguna bahasa Arab dalam persfektif I'rab Nahwu}

a) I'rab Rofa' / العلو والارتفاع

Nilai pada I'rab rofa' merupakan implementasi pendidikan karakter yang berorientasi pada gagasan stimulus respon dengan prinsip cita-cita tinggi di masyarakat. Secara mendasar nilai karakter dari rofa' adalah upaya sadar dan sistematis dari pengguna bahasa Arab untuk terlibat aktif dalam perannya di masyarakat.

Secara sadar, pengguna bahasa Arab memberikan stimulus atau bersedia terlibat mengawali dan mengikuti aneka ragam aktifitas yang bermanfaat, sehingga secara bersamaan masyarakat akan mampu menilai dan memberikan respon positif dari kinerja pengguna, lalu terjadilah interaksi sosial yang baik. 
Stimulus dan respon selain sebagai salah satu metode pembelajaran, juga dapat bermanfaat dalam proses pendekatan masyarakat bagi pengguna bahasa Arab, dengan mampu bergaul dengan masyarakat melalui pendekatan stimulus respon diharapkan dapat diterima dengan baik, sehingga kita mampu terlibat langsung dalam kegiatan, bahkan memberikan saran dan gagasan.

Dalam peribahasa "Gantungkan cita-citamu di langit", seolah membawa pembaca pada keniscayaan akan faktor utama kesuksesan pengguna bahasa Arab adalah semangat yang tinggi untuk memainkan perannya di masyarakat. Penulis mengutip sebuah petuah Ulama dalam syair Arab:

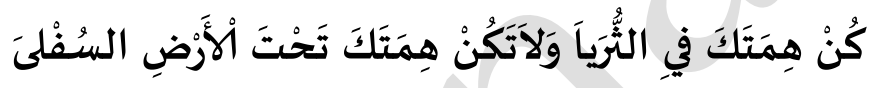

"Jadikan haparanmu menjulang setinggi bintang Suroya, jangan jadikan harapan itu terkubur di bawah tanah yang rendah".

Maka tampak jelas dari syair di atas bentuk rasionalisasi I'rab rofa' yang ciri utamanya dhomah atau yang biasa berbunyi "u". Sebagaimana diketahui bahwa dhomah posisinya di atas ( $\left.{ }^{\&}\right)$ yang secara etimologi artinya sesuatu yang tinggi/di atas. Tentu, menunjukan adanya kesamaan antara cita-cita dengan dhomah secara posisi. Keduanya, berada pada tempat yang tinggi.

Rasionalisasi kedua adalah dalam urutan I'rab bahwasanya rofa' menurut kesepakatan Ulama dalam berbagai kitab Nahwu selalu berada pada urutan pertama sebelum urutan tiga I'rab lainnya. Tentu hal ini juga berkaitan erat dengan pentingnya modal utama dalam memainkan peran di masyarakat yakni semangat dan memiliki cita-cita yang luhur sehingga hal itu harus dijadikan tujuan pertama dan utama.

Seiring dengan massifnya peran pengguna bahasa Arab di masyarakat, hal tersebut karena pengguna bahasa Arab memiliki ruh yang besar untuk terlibat berkontribusi dan memiliki cita-cita pembangunan yang tinggi di masyarakat. Seperti kedua rasionalisasi yang dikemukakan, bahwa dipandang penting pengguna bahasa Arab memiliki semangat yang besar untuk terlibat aktif dalam pembangunan masyarakat dengan nilai cita-cita pembangunan yang tinggi, bersedia berkorban juga motivasi yang besar untuk berkontribusi penuh.

Implementasi nilai-nilai I'rab rofa' menghendaki terciptanya mental pengguna bahasa Arab yang visioner dan aktif dalam merespon perubahan di masyarakat, 
mewujudkan cita-cita pembangunan nasional yang dinamis, juga penanaman pendidikan dengan spirit belajar dan motivasi yang besar.

\section{b) I'rab Nashab / إِستقامة والاستواء}

Nilai pada I'rab nashab merupakan implementasi pendidikan karakter yang berorientasi pada nilai integritas dan objektifitas. Pengguna bahasa Arab perlu dibangun dengan mental kerja yang memiliki integritas tinggi dan terukur secara objektifitas dalam perannya di masyarakat.

Upaya kedua ini melibatkan peran moral pengguna bahasa Arab, mereka dituntut untuk terlibat aktif sekaligus berupaya menjadi pribadi yang jujur, konsisten dan teladan bagi sesama. Memang tidak mudah, upaya ini perlu dilatih dan dilakukan secara kolektif, juga penanaman nilai I'rab nashab ini harus dimulai dari diri sendiri dan keluarganya.

Dalam bahasa agama, integritas adalah istikamah. Pengguna bahasa Arab, lebih mengenal istikamah. Istikamah merupakan term bahasa Arab yang berarti sikap komitmen yang dilakukan secara terus menerus, tidak terpengaruh, juga mampu menjawab tantangan tersulit sekali pun. Pada wilayah implementasi I'rab nashab dapat ditempuh dengan memiliki budaya etos kerja yang tinggi disertai konsistensi dan mandiri. Pengguna bahasa Arab dituntut untuk senantiasa mempunyai semangat dan gairah kerja tinggi yang diimbangi dengan integritas dan objektifitas dalam bekerja.

Integritas dan objektifitas dapat dilakukan dengan pembiasaan budaya kerja, yaitu berusaha kerja tepat waktu, meningkatkan disiplin, bekerja sesuai arahan, memperbaiki kinerja, mengupayakan produktifitas, menolak gratifikasi, dan menghindari celah yang dapat menyebabkan nilai kerja menurun. Dalam memainkan peran sosial di masyarakat, integritas dan objektifitas menjadi ruh kerja yang perlu terus dilatih dan dibiasakan. Sebagai pengguna bahasa Arab yang di dalam kalbunya terpatri bahasa Alquran, maka diharapkan mampu mewujud menjadi karakter positif dalam kehidupannya.

\section{c) I'rab Khofad / التواضع والخضوع}

Nilai pada I'rab khofad adalah pendidikan karakter yang berorientasi pada sikap rendah hati dan apresiatif. Langkah ketiga karakter pengguna bahasa Arab -secara 
hirarkis I'rab Nahwu- yaitu khofad, khofad memang secara terminologi dapat berarti kesedian untuk bersikap rendah hati dan tawadlu.

Upaya ini akan menjelma dalam bentuk kesedian untuk bersikap rendah hati dalam bekerja, menghindari persaingan tidak sehat, mengurangi ketergantungan dengan pihak lain serta bersikap menghargai dan menghormati kinerja pihak lain dengan baik. Dalam peran di masyarakat, pengguna bahasa Arab juga harus bersedia mengakui dan mengapresiasi hasil kerja pihak lain, mengedepankan nilai rendah hati dan apresiatif, ini merupakan etika kerja yang harus terus dibangun, dan dilestarikan.

Upaya penanaman budaya kerja saling menghormati dan konstruktif adalah wujud implementasi I'rab khofad. Tantangan di dunia kerja terkadang menghendaki munculnya prilaku amoral, bersaing secara tidak sehat bahkan praktik kerja yang tidak terpuji -seperti suap menyuap dan korupsi- seolah rahasia umum dan menjadi tantangan yang sangat berat. Maka, pengguna bahasa Arab harus dibentengi secara moral dengan nilai filosofis I'rab khofad, paling tidak dapat mencegah munculnya mental persaingan kerja yang tidak sehat, serta membudayakan sikap saling menghormati dan menghargai hasil kerja pihak lain sebagai wujud sikap terpuji.

\section{d) I'rab Jazm / القطع}

Nilai pada I'rab jazm adalah pendidikan karakter yang berorientasi pada nilai khidmat ilmiyyah (bakti ilmu). Sebagai puncak hirarkis filosofis I'rab Nahwu, jazm menjadi nilai ruh utama pengguna bahasa Arab, karena berakar pada kekuatan niat dan orientasi kerja. Seperti pada terminologi, bahwa jazm bermakna putus atau tidak terikat. Secara sederhana, dapat dimaknai secara tersirat bahwa nilai kerja pengguna bahasa Arab harus berorientasi pada nilai ibadah. Karena boleh jadi, orientasi kerja sementara pihak- sedikit bergeser hanya untuk kepentingan memperoleh materi, gaji dan gengsi saja dari masyarakat.

Pendekatan nilai ruhani dalam bingkai ikhlas dan amanah harus terus didakwahkan dan dimulai dari pengguna bahasa Arab secara khusus. Pembiasaan kerja yang didasari nilai ibadah memang harus dibudayakan, disosialiasikan dan dilestarikan dalam wujud kerja pengguna bahasa Arab.

\section{E. Penutup}


Berdasarkan uraian di atas, kesimpulan penelitian ini bahwa hirarkis I'rab Nahwu sangat bermanfaat bagi implementasi nilai karakter pengguna bahasa Arab dengan pendekatan kontekstual yaitu memiliki spirit pembangunan yang tinggi, interaksi sosial yang aktif dan dinamis, berintegritas tinggi, objektif, rendah hati dan apresiatif terhadap prestasi pihak lain juga budaya kerja yang beririentasi pada nilai ibadah dalam kerangka ikhlas dan amanah. Secara mendasar penelitian ini berangkat dari kebutuhan akan nilai-nilai pendidikan karakter yang perlu ditanamkan bagi pengguna bahasa Arab. Sehingga nilai-nilai filosofis (makna tersirat) dari I'rab Nahwu diharapkan mampu menjadi tata nilai untuk implementasi moral pengguna bahasa Arab. Secara kontekstual diharapkan mampu mewakili akan ketersedian nilai-nilai karakter yang diimplementasikan oleh para pengguna bahasa Arab dalam perannya di masyarakat Indonesia. 


\section{DAFTAR PUSTAKA}

Al-Kafrawy, S. H. (tt). al-Kafrawy ala Matn al-Jurûmiyyah. Sanqofuroh Jeddah: al-Haramain.

Al-Asymawy, S. A. F. (tt). Asymawiy. Semarang: Maktabah Ulumiyah.

Al-Quhin, S. A. (2020). Nahwu Sufi Linguistik Arab dalam Persfektif Tasawuf. Bekasi: Al-Muqsith Pustaka.

Bahruddin, U. (2010). Tathwîr Manhaj Ta'lîm al-Lughah al-'Arabiyah. Malang: UIN Maulana Malik Ibrahim Malang Press.

Chaer, A. (2019). Psikolinguistik Kajian Teoretik. Jakarta: Penerbit Rineka Cipta.

Gunawan, I. (2013). Metode Penelitian Kualitatif, Teori dan Praktik. Jakarta: Bumi Aksara

Hazuar. (2019). Konsep I'rab dalam Pandangan Ibrahim Musthafa dan Ibrahim Anis. Jurnal Arabiyatunâ, vol. 3, no. 1, Mei 2019.

HIMMPAS UPI. (2016). Pendidikan Untuk Peradaban. Bandung: Rizqi Press.

Izzan, A. (2011). Metodologi Pembelajaran Bahasa Arab. Bandung: Humaniora.

Madjid, N. (2013). Islam Kemoderenan dan Keindonesiaan. Bandung: Mizan.

Nuh, M. (2013). Menyemai Kreator Peradaban. Jakarta: Zaman.

Pransiska, T. (2015). Konsep I'rab dalam Ilmu Nahwu. Jurnal al-Mahâra. vol. 1, no. 1, Desember 2015.

Rosidin, D. (2015). Pendidikan dalam Al-Quran. Bandung: Insan Rabbani.

Tafsir, A. (2017). Filsafat Pendidikan Islam. Bandung: ROSDA.

Tamam, A. M. (2019). Bangsa dan Bahasa Arab dalam Lintasan Sejarah. Yogyakarta: LeKKas. 